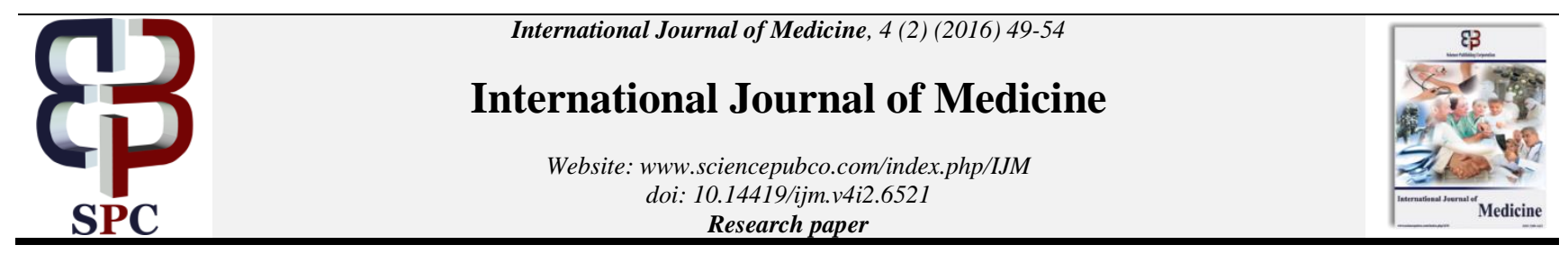

\title{
What factors influence the choice of first healthcare provider for childhood fever or cough in Ghana?
}

\author{
Mustapha Immurana ${ }^{1}$, Arabi, $\mathbf{U}^{2}$ \\ ${ }^{1}$ Research Scholar, Department of Economics, Mangalore University, Mangalagangotri-574119, Karnataka State, India \\ ${ }^{2}$ Professor and Research Guide, Department of Economics, Mangalore University, Mangalagangotri - 574119, Karnataka State, India \\ *Corresponding author E-mail: mustaphaimmurana@gmail.com
}

\begin{abstract}
Malaria and Pneumonia are major killers of children underfive. However, fever and cough are major signs of Malaria and Pneumonia respectively and hence making proper management of fever and cough indispensable in the fight against underfive mortality. This study therefore investigated the factors that influence the choice of first healthcare provider for children with fever or cough in Ghana. The study used the 2014 Ghana Demographic and Health Survey (GDHS) as the main source of data. By employing the multinomial probit model, the study found that urban children, children with higher birth rank, older children, children from the Ga/Dangme, Akan, MoleDagbani, Ewe, Mande and Gurma ethnicity and children of mothers with big problems with regards to permission and distance to seek self-medical care were more likely to be given self-medication or to be sent to a traditional practitioner initially for fever or cough. Contrary, mothers with health insurance, aging mothers and wealthy households were less likely to first resort to self-medication or a traditional practitioner in order to seek care for children with fever or cough. The study therefore concludes that ethnicity, residence, permission and distance to seek medical care by mother, mother's health insurance, household wealth, child's age, mother's age and birth order are the factors that influence the choice of first healthcare provider for children with fever or cough in Ghana.
\end{abstract}

Keywords: Child Health; Choice of First Healthcare Provider; Ghana.

\section{Introduction}

World leaders came together in 2015 to set the sustainable development goal (SDG) 3.2 which aims at reducing underfive deaths to 25 per thousand live births by 2030 . This was not surprising since according to the World Health Organisation (WHO, 2016), it is estimated that 5.9 million children underfive died in 2015 with Malaria and Pneumonia as some of the leading causes of these deaths.

Pneumonia which has cough as some its signs together with some respiratory tract infections (ARIs) are major causes of mortality in younger Ghanaian children. However, with regards to pneumonia, early detection and treatment can help avoid most of the mortalities due to ARIs (Ghana Statistical Service [GSS], Ghana Health Service [GHS] \& ICF International, 2015).

Also in children, fever is an indication of malaria which is one of the major causes of deaths in sub-Saharan Africa and remains a public health challenge in Ghana with pregnant women and children underfive being the most vulnerable. The worrying aspect is that, the burden of Malaria is not restricted to only the health sector but transcends to the social and economic sectors as well (GSS, GHS \& ICF International, 2015). Therefore bettering the management of fever would not only reduce the irrelevance of antimalarial drugs use but in addition, would ensure suitable treatment and referral of non-malaria febrile sickness and hence reducing mortality and morbidity (WHO, 2013).

Given that fever and cough are major signs of malaria and pneumonia respectively, it became relevant for an investigation to be conducted on the factors that influence the choice of first health care provider for children underfive with fever or cough in Ghana.
This is very important in the sense that stakeholders and policy makers need to know the drivers of choice of first healthcare providers for children in order to attain the goal of increasing appropriate health seeking behaviour for children towards attaining the SDG 3.2 by 2030 .

\section{Literature review}

On the literature, the main theoretical basis of the work is the demand for health as posited by Grossman (1999) where medical care would basically be sought not for its own sake but to produce good health. This medical care according to Grossman is also a form of investment since healthy people would perform better both in the market and non-market sectors. Thus in the case of children, proper health seeking behaviours for them now, would help them grow to build the human capital base of any country and hence economic growth and development at large.

On the empirical front, Kanté et al. (2015) revealed in rural Tanzania that educated mothers/caregivers and wealthy households were less likely to resort to no or home medication for children. However, distance (greater than $1 \mathrm{~km}$ ), being older (2 years and above), having two or more children less than five years of age were found to increase the likelihood of children receiving no or home medication. Kassile, Lokina, Mujinja and Mmbando (2014) in central Tanzania found that staying with single parents or the absence of both parents, having 2 to 3 underfive children and longer distance $(5 \mathrm{~km}$ or greater) decreased the likelihood of seeking early care for children. Dey and Mishra (2014) in India found that the uneducated, females, rising age, lower income earners and those from the weaker portions of society were more likely to opt 
for public health care providers as compared to private providers. Tiehi (2012) revealed in Côte d'Ivoire that having male household heads decreased the usage of modern services whiles richer homes and highly educated homes chose private care. In addition, the choice to use modern services was revealed to be positively influenced by distance whiles consultation fee negatively influenced the demand for child care. Amaghionyeodiwe (2008) revealed among other findings that, monetary prices and distance from the facility decreased the choice of using modern healthcare providers in Nigeria.

Specifically on Ghana, Boachie (2016) in the Kumasi metropolis and Kwabre East District of Ghana found additional charges, income, age, clean environment, reputation, availability of drugs, waiting time, availability of doctors, residence and gender to influence the choice of preferred health care providers for enrolees under the Ghana National Health Insurance scheme. Fenny, Asante, Enemark and Hansen (2015) in three Districts of Ghana among other findings, revealed that having a health insurance increased the choice of formal care over informal healthcare. Having secondary education was also found to increase the utilisation of private hospitals/clinics and public health centres/clinics over informal care whiles wealth status of the household was revealed to influence the usage of regional/district hospitals over informal providers. Arthur (2014) revealed that higher wealth status and maternal health insurance increased the likelihood of receiving care for children from a Government health facility. Also rural household children excluding those with maternal health insurance were more probable to get traditional or self-medication whiles increases in mothers age and birth rank were revealed to increase and decrease the probability of using private/mobile clinics and traditional/self-medication respectively. Further, maternal unemployment was also found to increase the usage of traditional/selfmedication for children. Krumkamp et al. (2013) in a study in Ghana (Asante Akim North District) found that distance (to a facility) had a negative influence on attending hospital whiles health insurance influenced the willingness with regards to seeking care from a hospital. Nonvignon et al. (2010) in the Dangme West District of Ghana found that longer waiting, treatment and travel time influenced the use of self-medication and over the counter providers relative to private and public providers for children. Further, Higher Income was revealed to influence the utilisation of private and public facilities or providers relative to selfmedication for children. Also male and female children were revealed to respectively receive care from public providers and selfmedication. Finally health insurance was found to influence caregivers to seek care for children from public facilities or providers as compared to over the counter or private providers. Kuunibe and Dary (2010) found that distance to the facility, waiting time and cash amount paid decreased seeking care from orthodox sources among insured persons in the Upper West region of Ghana. Dzator and Asafu-Adjaye (n.d.) in Amasaman and Hohoe of Ghana among other findings revealed that, education influenced the choice of private provider care over self-medication.

However, with regards to the studies on Ghana, only Arthur (2014), Krumkamp et al. (2013), and Nonvignon et al. (2010) entirely focused on the choice of health providers of children. Further, apart from Arthur (2014) who used the 2008 Ghana Demographic and Health Survey (GDHS), none of the studies on Ghana used data that had nationwide representation. This study therefore is unique and timely in the sense that it used the most recent demographic and health survey on Ghana (2014 GDHS) as the source of data which reflects the current situation better. Moreover, the paper included variables like religion, ethnicity and permission to seek medical care for mother which were not included in Arthur (2014), Krumkamp et al. (2013) and Nonvignon et al. (2010). Thus since the United Nations Development Programme [UNDP] \& Government of Ghana [GOG]/National Development Planning Commission [NDPC], (2015) reported sociocultural factors as one of the challenges in combatting child mortality in Ghana, this paper added religion, ethnicity, and permission to get access to medical care for mother as additional proxies for social-cultural factors in order to examine how they influence the choice of first healthcare provider for childhood fever or cough

\section{Data and methods}

The 2014 GDHS which was a cross-sectional survey conducted in Ghana from early September to mid-December 2014 was the main source of data for the study. The 2014 GDHS is actually the most recent nationally representative demographic and health survey in Ghana. During the survey, information on women with regards to their socio-economic background and that of their children underfive was collected. Specifically, mothers were asked whether their children suffered from fever and cough two weeks prior the survey and if so where was the first place they were sent for treatment. It must however be noted that, the dependent variable used in this study was the first place sought treatment for childhood fever or cough.

This study categorized the Healthcare Providers in to three. These involved Government clinic/health center, Government hospital/poly clinic and Government health post/chips (Public or Government health Facility) as the first category. The second one was made up of field worker, mobile clinic, private doctor/hospital/clinic and maternity home (Private health facility or provider/field worker/mobile clinic/maternity home) and the third category involved chemical drug store, pharmacy, drug peddler, shop/market, traditional practitioner and other (Selfmedication/Traditional). The first, second and third categories were recoded as 1,2 and 3 respectively. All don't know answers were regarded as missing values. In addition household wealth status, maternal marital status and religion were recoded from their initial nature in the data. All other categorical explanatory variables were treated as dummy variables. The dependent variable of the study therefore was the First healthcare provider chosen by caregivers for childhood fever or cough as categorized above. It must be noted that choices of healthcare providers are assumed to be made on behalf of children by mothers/caregivers since they are too young to make decisions on their own.

Since the healthcare providers were categorized in to three unranked choices, the study adopted the Multinomial Probit (MNP) model in order to find out the factors that influence the choice of first healthcare provider for children with fever or cough in Ghana Therefore as outlined in Greene (2012) whiles still maintaining the symbols or notations in Greene (2012), the MNP model is of the structural equations:

$$
\mathrm{U}_{\mathrm{ij}}=\mathrm{X}_{\mathrm{ij}}^{\prime} \beta+\varepsilon_{\mathrm{ij}}, \mathrm{j}=1, \ldots, \mathrm{J},\left[\varepsilon_{\mathrm{i} 1}, \varepsilon_{\mathrm{i} 2}, . ., \varepsilon_{\mathrm{ij}}\right] \sim \mathrm{N}[0, \Sigma]
$$

Where Uij is the expected utility of caregiver/mother i for selecting healthcare provider $\mathrm{j}, \mathrm{X}$ represents the explanatory variable, and the coefficient of the explanatory variable is $\beta$ and $\varepsilon$ is the disturbance term. It must be noted that we can have several explanatory variables and hence several coefficients.

Therefore choosing option (alternative) q by a mother/caregiver gives a term in the log-likelihood as:

$\operatorname{Prob}\left[\right.$ option $\left._{\mathrm{iq}}\right]=\operatorname{Prob}\left[\mathrm{U}_{\mathrm{iq}}>\mathrm{U}_{\mathrm{ij}}, \mathrm{j}=1, \ldots, \mathrm{J}, \mathrm{j} \neq \mathrm{q}\right]$

Hence the likelihood of selecting health provider q over $\mathrm{j}$ by caregiver/mother i will be

Prob [option $\left.{ }_{\mathrm{iq}}\right]=\operatorname{Prob}\left[\varepsilon_{\mathrm{il}}-\varepsilon_{\mathrm{iq}}<\left(\mathrm{x}_{\mathrm{iq}}-\mathrm{x}_{\mathrm{il}}\right)^{\prime} \beta, . ., \varepsilon_{\mathrm{iJ}}-\varepsilon_{\mathrm{iq}}<\left(\mathrm{x}_{\mathrm{iq}}-\right.\right.$ $\left.\left.\mathrm{x}_{\mathrm{iJ}}\right)^{\prime} \beta\right]$

Thus a mother/care giver would make a healthcare provider as the first choice if it gives her the highest expected utility. The MNP was adopted because it relaxes the independence restriction assumption of the Multinomial logit model as stated in Greene (2012). 


\section{Results and discussion}

\subsection{Descriptive statistics with Pearson chi square}

This section looked at how the various choices of healthcare providers were distributed among the various categorical independent variables as well as testing the statistical significance of the relationships between the choice of first health care provider and the categorical explanatory variables.

Thus Univariate analysis using the Pearson's Chi-square test was done to find out whether there was any statistically significant difference within the various independent variables and the first choice of Healthcare provider for childhood fever or cough in Ghana. The results showed that there were no significant relation- ships between the choice of first healthcare provider for childhood fever or cough and sex of the child, sex of household head, permission to seek medical care by mother, mother's employment and religion. However, there were significant relationships between the choice of first healthcare provider for childhood fever or cough and ethnicity, residence, mother's education, mother's insurance, distance and money to seek medical help by mother and household wealth status. Also the results among others showed that most rural and urban children were sent to government facilities. Also most rich and non-rich household children were sent first to a government facility for fever or cough.

\subsection{Regression analysis}

Table 1: Univariate Analysis of Choice of First Healthcare Provider for Childhood Fever or Cough in Ghana

\begin{tabular}{|c|c|c|c|c|}
\hline Variable & $\begin{array}{l}\text { Government Facility } \\
(\%)\end{array}$ & $\begin{array}{l}\text { Private health facility or provid- } \\
\text { er/fieldworker/mobile clinic/maternity home (\%) }\end{array}$ & $\begin{array}{l}\text { Self-medication } \\
\text { /traditional }(\%)\end{array}$ & Chi-square test \\
\hline Residence & & & & $34.5101 * * *$ \\
\hline Urban & 51.58 & 13.16 & 35.26 & \\
\hline Rural & 68.67 & 4.88 & 26.45 & \\
\hline Religion & & & & 2.4064 \\
\hline Christian & 62.07 & 8.98 & 28.95 & \\
\hline Muslim & 59.91 & 7.08 & 33.02 & \\
\hline Traditional & 61.82 & 5.45 & 32.73 & \\
\hline Akan & 55.42 & 10.84 & 33.75 & \\
\hline $\mathrm{Ga} /$ Dangme & 44.19 & 23.26 & 32.56 & \\
\hline Ewe & 53.57 & 6.25 & 40.18 & \\
\hline Guan & 65.22 & 21.74 & 13.04 & \\
\hline Mole-Dagbani & 69.26 & 4.24 & 26.50 & \\
\hline Grusi & 84.44 & 0.00 & 15.56 & \\
\hline Gurma & 66.67 & 1.85 & 31.48 & \\
\hline Mande & 72.22 & 5.56 & 22.22 & \\
\hline Mother's Education & & & & $26.4706^{* * * *}$ \\
\hline Uneducated & 67.18 & 3.72 & 29.10 & \\
\hline Primary & 65.54 & 5.65 & 28.81 & \\
\hline Secondary & 55.73 & 12.80 & 31.47 & \\
\hline Higher & 52.63 & 15.79 & 31.58 & \\
\hline Mother's Insurance & & & & $9.6585 * * *$ \\
\hline Uninsured & 53.85 & 8.50 & 37.65 & \\
\hline Insured & 64.41 & 8.26 & 27.33 & \\
\hline Marital Status & & & & $9.9001 * * *$ \\
\hline Single & 54.49 & 10.63 & 34.88 & \\
\hline Married & 65.03 & 7.19 & 27.78 & \\
\hline Mother's Employment & & & & 1.4876 \\
\hline Unemployed & 57.32 & 8.92 & 33.76 & \\
\hline Employed & 62.47 & 8.22 & 29.31 & \\
\hline $\begin{array}{l}\text { Permission to seek } \\
\text { medical care/help by } \\
\text { mother }\end{array}$ & & & & 2.4709 \\
\hline $\begin{array}{l}\text { Money to seek medical } \\
\text { care/help by mother }\end{array}$ & & & & $6.5948 * *$ \\
\hline Big Problem & 60.26 & 6.55 & 33.19 & \\
\hline Not a Big Problem & 62.86 & 10.11 & 27.03 & \\
\hline $\begin{array}{l}\text { Distance to seek medi- } \\
\text { cal care/help by mother }\end{array}$ & & & & $5.0014 *$ \\
\hline Big Problem & 58.18 & 7.27 & 34.55 & \\
\hline Not a Big Problem & 63.46 & 8.92 & 27.62 & \\
\hline Sex of Household Head & & & & 1.0560 \\
\hline Male & 62.44 & 7.90 & 29.66 & \\
\hline Female & 59.09 & 9.50 & 31.40 & \\
\hline Sex of Child & & & & 0.6911 \\
\hline Male & 60.82 & 7.96 & 31.22 & \\
\hline Female & 62.41 & 8.75 & 28.84 & \\
\hline Wealth Status & & & & $56.9176 * * *$ \\
\hline Non-Rich & 66.62 & 4.47 & 28.91 & \\
\hline Rich & 47.52 & 19.01 & 33.47 & \\
\hline
\end{tabular}

Source: Authors computation from the 2014 GDHS. Notes: 1. ***, and *** showing significant difference at $10 \%, 5 \%$ and $1 \%$ respectively within the predictor and choice of first health care provider for childhood fever or cough. 2 . Traditional in this study means traditional/ spiritualist/no religion. 
Table 2: Multinomial Probit Results on Determinants of Choice of First Healthcare Provider for Childhood Fever or Cough in Ghana with SelfMedication/Traditional Practitioner as the Base Category

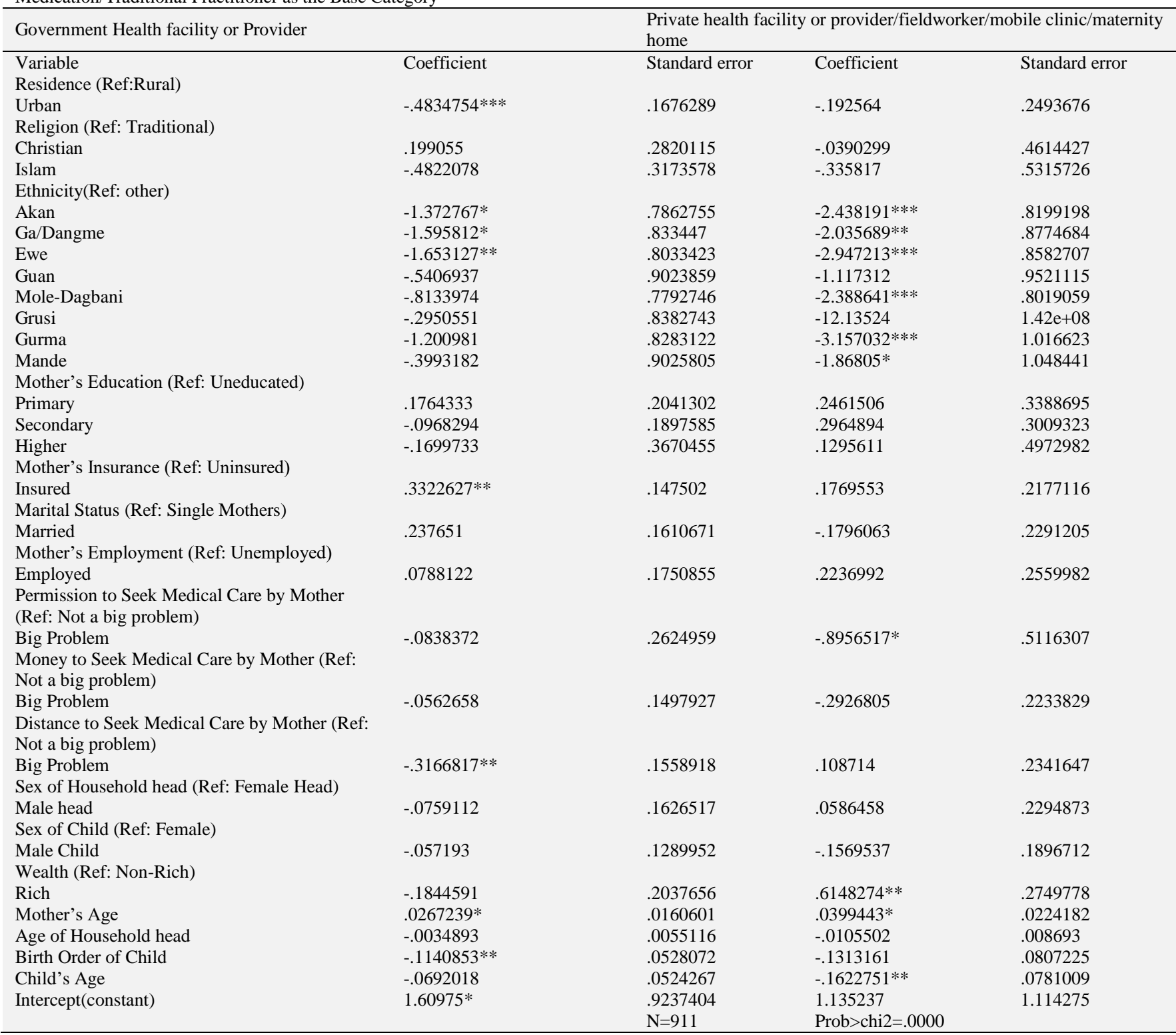

Source: Authors computation from the 2014 GDHS. Notes: 1 . ***P-value<.01, **P-value<.05, *P-value<.1, 2. Traditional in this study means traditional/ spiritualist/no religion.

The multivariate analysis (regression) was done to find out the factors which influence the choice of first health care provider for childhood fever or cough in Ghana whiles controlling for other factors which influence the choice of first healthcare provider.

The results showed that, urban children were less likely to be sent to a Government facility relative to Self-medication/Traditional practitioner. Thus children from urban areas who had fever or cough were more probable to receive care from Selfmedication/Traditional practitioner which is similar to the findings of Tiehi (2012) in Côte d'Ivoire and contrary to that of Arthur (2014) who revealed that rural mothers without health insurance opted for traditional or self-medication for their children in Ghana. This result can be attributed to the congestion in government health facilities in urban areas which may end up increasing waiting time and hence deterring mothers from seeking care for their children from Government facilities.

Given the negative significant (i.e. either $1 \%, 5 \%$ or $10 \%$ ) nature of the coefficients of Ewe, Akan and Ga/Dangme ethnicities under both Private health facility or provider/field worker/mobile clinic/maternity home and Government facility, they implied that children from Ewe, Akan, and $\mathrm{Ga} /$ Dangme ethnicity were less likely to have been first sent to a Private health facility or provider/field worker/mobile clinic/maternity home and Government facility as compared to Self-medication/Traditional practitioner
Therefore children with Ewe, Akan and Ga/Dangme ethnicity who suffered from fever or cough were more probable to receive care first from Self-medication/Traditional sources. Also the negative significant coefficients of children from Mole-Dagbani (1\%), Mande (10\%) and Gurma (1\%) ethnic groups with regards to Private health facility or provider/field worker/mobile clinic/maternity home implied that children from Mole-Dagbani, Gurma and Mande ethnicities were more likely to receive their first care from Self-medication/Traditional sources relative to Private health facility or provider/field worker/mobile clinic/maternity home. These points out the significance of ethnicity as a proxy for socio-cultural factors in seeking care for children. Thus it could be that these ethnic groups have so much believe in traditional sources/self-medication relative to the other health providers or facilities. Thus some ethnic groups might have the belief that seeking care from traditional practitioners in particular is part of the cultural values and norms bequeathed to them by their forefathers and hence must not be abandoned.

Maternal health insurance under Government Health facility had a positive 5\% significant coefficient of .3322627 . Thus mothers with health insurance were more likely to have sent their children with fever or cough initially to Government health facilities relative to Self-medication/Traditional sources. This can be attributed to the fact that all government health facilities are health insurance 
providers under the national health insurance scheme in Ghana which has a free child and maternal health insurance membership policy as well as the highest number of subscribers. Thus maternal insurance increases the likelihood of seeking care for children with fever or cough initially from government health facilities. This is similar to the findings on Ghana by Arthur (2014), Nonvignon et al. (2010), Fenny et al. (2015) in the case formal care providers and Krumkamp et al. (2013) with regards to seeking care in the hospital.

Mothers with big problems in getting permission to seek selfmedical care were revealed to be more likely to first resort to selfmedication/Traditional practitioners for childhood fever or cough relative to Private health facility or provider/field worker/mobile clinic/maternity home. Thus since mothers normally seek care for their children, if there are difficulties in securing permission to seek medical care for mothers, it would affect child health seeking behaviour negatively. This further lends credence to the effect of socio-cultural factors on child health seeking behaviour.

Since distance to health facility as a big problem was negatively significant at 5\% with regards to Government Health facility, it implied that mothers with distance challenges with regards to health facilities were less likely to utilize Public or Government facilities as the first treatment option for children with fever or cough. Thus they were more likely to resort to selfmedication/traditional source. The implication is that, the longer the distance to the facility, the more the cost in terms of transportation, stress as well as time lost for not working and hence deterring the usage of Government health facilities. This is similar to the findings of Kanté et al. (2015) in rural Tanzania, Kassile et al. (2014) in central Tanzania, and Krumkamp et al. (2013) and contrary to that of Tiehi (2012) in Côte d'Ivoire.

The positive 5\% significant coefficient of wealthy households under Private health facility or provider/field worker/mobile clinic/maternity home implied that children from wealthy households were less likely to have received the very first care for fever or cough from self-medication/traditional practitioner relative to Private health facility or provider/field worker/mobile clinic/maternity home. Thus they were more likely to have received their first treatment from a Private health facility or provider/field worker/mobile clinic/maternity home. This is not surprising since wealthy households can better afford the services of such facilities relative to the non-rich households. This is similar to the findings of Tiehi (2012) and Nonvignon et al. (2010).

Also increasing mothers' age (positive coefficient significant at $10 \%$ ) was revealed to increase the probability of children with fever or cough receiving their first care from a Government health facility and Private health facility or provider/field worker/mobile clinic/maternity home relative to self-medication or traditional practitioner. This is because aging mothers might have given birth severally and hence have better experiences with regards to appropriate child health seeking behaviour relative to younger mothers. This finding is similar to the results of Arthur (2014) in the case of private or mobile clinics.

The negative coefficient of birth order which was significant at $5 \%$ implied that increasing birth order decreased the likelihood of children being sent first to a government health facility relative to self-medication/traditional source. Thus seeking care first from self-medication/traditional practitioner for children with fever or cough increased with increasing birth order. This finding conflicts that of Arthur (2014) and could be explained by the reason that, mothers might think they have had enough experiences in taking good care of their children from their previous births and hence would prefer self-medication for their subsequent births. However, this is disturbing because subsequent births equally need more appropriate health care since mothers would be aging and hence would not be healthy as the case of their previous births when they were relatively younger. Also it could be that mothers would be relying on medicines prescribed for their previous births for cough or fever, and hence may not send their subsequent children (births) to a health facility or provider since they can easily buy these previously prescribed drugs in order to give to their subsequent births for cough or fever.

Further, the results showed that, as the age of the child (with a negative 5\% significant coefficient of -.1622751) increased, it was less probable for care to be sought first from a Private health facility or provider/field worker/mobile clinic/maternity home relative to self-medication/traditional practitioner. Thus rising age of the child increased the likelihood of first seeking care via selfmedication/traditional practitioner for fever or cough. This is similar to the finding of Kanté et al. (2015) in rural Tanzania. Thus caregivers might think that, as their children grow, they wouldn't need to send them to such facilities and hence may resort to selfmedication given that, they might see older children to be less susceptible to diseases. Also it might be that mothers might think they have gained enough experience for sending their children with fever or cough to appropriate health facilities when they were younger and hence may resort to self-medication as their children grow by trying to go and buy medicines that was prescribed to them previously upon seeing signs of fever or cough.

\section{Conclusion}

From the results, this study concludes that ethnicity, residence, permission and distance to seek medical care by mother, mother's health insurance, household wealth, child's age, mother's age and birth order are the factors that influence the choice of first healthcare provider for children with fever or cough in Ghana.

Therefore building of more health facilities in urban areas could help solve the resort to self-medication/Traditional practitioners for childhood fever or cough among urban children. Thus, reducing waiting time due to congestion in Government health facilities in urban areas and hence making caregivers not to opt for selfmedication/traditional practitioners for treatment for their children. Adopting Behavior Change Communication (BCC) strategies on the need to seek proper care with various ethnic rulers as major stakeholders should be instituted since Ga/Dangme, Akan, MoleDagbani, Ewe, Mande and Gurma ethnicity children with fever or cough were more likely to be given self-medication or sent to a traditional practitioner. The BCC should also educate mothers on the need to seek care from appropriate sources for children irrespective of age and birth order. This is because rising child's age and birth order increased the likelihood of resorting to selfmedication/Traditional practitioner for childhood fever or cough.

New measures towards expanding and encouraging enrolment on the already existing free maternal health insurance membership under the National health insurance scheme should be instituted since mother's insurance reduced the likelihood of first resorting to self-medication/traditional practitioner for children with fever or cough.

Educating heads of households and empowering women could be an effective policy drive towards using appropriate healthcare. This is because mother's who had big problems in getting permission to seek self-medical care were more likely to first resort to self-medication/traditional practitioner for childhood fever or cough.

Finally, building hospitals very close to communities and ensuring good roads linking communities to health facilities should be implemented. This is because big problems with regards to distance to the health facility, deterred the usage of Government health facilities or providers relative to self-medication/traditional practitioner for childhood fever or cough.

\section{Acknowledgement}

The authors are thankful to the DHS program for the data. 


\section{Conflicts of interest}

None.

\section{References}

[1] Amaghionyeodiwe AL (2008) Determinants of the choice of health care provider in Nigeria. Health Care Manage Sci, 11, 215-227. http://dx.doi.org/10.1007/s10729-007-9038-3.

[2] Arthur E (2014) socioeconomic correlates and the choice of treatment for childhood fever in Ghana. African Population Studies, 28 (2 Supplement) July 2014. http://dx.doi.org/10.11564/28-0-548.

[3] Boachie MK (2016) Preferred primary healthcare provider choice among insured persons in Ashanti Region, Ghana. International Journal of Health Policy and Management, 5(3), 155-163. http://dx.doi.org/10.15171/ijhpm.2015.191.

[4] Dey KD \& Mishra V (2014) Determinants of Choice of Healthcare Services Utilization: Empirical Evidence from India. Indian Journal of Community Health, 26(04).

[5] Dzator J \& Asafu-Adjaye J (n.d.). A study of malaria care provider choice in Ghana.

[6] Fenny PA, Asante AF, Enemark U, \& Hansen SK (2015) Malaria care seeking behavior of individuals in Ghana under the NHIS: Are we back to the use of informal care. BMC Public Health, 15(370). http://dx.doi.org/10.1186/s12889-015-1696-3.

[7] Ghana Statistical Service (GSS), Ghana Health Service (GHS), \& ICF International (2015). Ghana Demographic and Health Survey 2014. Rockville, Maryland, USA: GSS, GHS, and ICF International.

[8] Greene HW (2012) Econometric Analysis. 7th edition, International Edition, Prentice Hall, Pearson Education, Edinburgh Gate, Harlow Essex CM20 2JE, England.

[9] Grossman M (1999) the Human Capital Model and the Demand for Health. NBER Working Paper No. 7078.

[10] Kanté MA, Gutierrez RH, Larsen MA, Jackson FE, Helleringer S, Exavery A, Tani K, \& Phillips FJ (2015) Childhood Illness Prevalence and Health Seeking Behavior Patterns in Rural Tanzania. BMC Public Health, 15(951). http://dx.doi.org/10.1186/s12889015-2264-6

[11] Kassile T, Lokina R, Mujinja P \& Mmbando PB (2014) Determinants of delay in care seeking among children under five with fever in Dodoma region, central Tanzania: a cross sectional study. Malaria Journal, 13(348). Retrieved from http://www.malariajournal.com/content/13/1/348. http://dx.doi.org/10.1186/1475-2875-13-348.

[12] Krumkamp R, Sarpong N, Kreuels B, Ehlkes L, Loag W, Schwarz GN, May J (2013) Health Care Utilization and Symptom Severity in Ghanaian Children - a Cross-Sectional Study. PLoS ONE 8(11) e80598. http://dx.doi.org/10.1371/journal.pone.0080598.

[13] Kuunibe N \& Dary KS (2012) Choice of Healthcare Providers among Insured Persons in Ghana. Research on Humanities and Social Sciences, 2(10)

[14] Nonvignon J, Aikins SKM, Chinbuah AM, Abbey M, Gyapong M, Garshong ANB, Gyapong OJ (2010) Treatment choices for fevers in children under-five years in a rural Ghanaian district. Malaria Journal, 9(188). $\quad$ Retrieved from http://www.malariajournal.com/content/9/1/188. http://dx.doi.org/10.1186/1475-2875-9-188.

[15] Tiehi NT (2012) Demand for Child Healthcare in Cote d'Ivoire: A Multinomial Probit Analysis. International Review of Business Research Papers, 8 (6), 113 - 125

[16] UNDP \& GOG/NDPC (2015) 2015 Ghana Millennium Development Goals report.

[17] World Health Organization (2016) Children: Reducing Mortality. Fact Sheet updated January, 2016. Accessed from: http://www.who.int/mediacentre/factsheets/fs178/en/ on 7th April, 2016

[18] World Health Organization (2013) WHO Informal Consultation on Fever Management in Peripheral Health Care Settings: a Global Review of Evidence and Practice. WHO Library Cataloguing-inPublication Data. ISBN 9789241506489 